\title{
PROPOSIÇÃO DE UMA METODOLOGIA ESTRUTURADA DE AVALIAÇÃO DO POTENCIAL REGIONAL DE REÚSO DE ÁGUA: 03 - METODOLOGIA DE POTENCIALIDADES (DEMANDAS E OFERTAS) E ANÁLISE ESPACIAL
}

\author{
TOWARDS A STRUCTURED METHODOLOGY FOR ASSESSING REGIONAL WATER REUSE \\ POTENTIAL: 03 - METHODOLOGY OF POTENTIALITY (DEMANDS AND OFFERS) AND \\ SPATIAL ANALYSIS
}

Luis Carlos Soares da Silva Juniora, Maíra Araújo de Mendonça Lima ${ }^{b}$, Pablo da Silva Avelarc, Ana Sílvia Pereira Santos ${ }^{b}$, Sérgio Rodrigues Ayrimoraes Soares ${ }^{d}$, Ricardo Franci Gonçalves ${ }^{e}$, José Manuel Pereira Vieiraf.

a Universidade Federal do Rio de Janeiro, ${ }^{b}$ Universidade do Estado do Rio de Janeiro, ${ }^{c}$ Empresa Baiana de Água e Saneamento, ${ }^{d}$ Agência Nacional de Águas e Saneamento Básico, ${ }^{e}$ Universidade Federal do Espírito Santo, ${ }^{f}$ Universidade do Minho

\section{luis.junior@coc.ufri.br,mairalima.90@gmail.com, pablo.avelar@embasa.ba.gov.br,ana.pereira@ueri.br. ssoares@ana.gov.br,rfg822@gmail.com,jvieira@civil.uminho.pt.}

Submissão: 05 de março de 2021 Aceitação: 1 de julho de 2021

\section{Resumo}

O reúso de água é um tema de larga difusão e desenvolvimento em várias regiões do mundo. No Brasil, a sua aplicação é recente e ainda incipiente. Dessa forma, o país ainda deve construir a sua própria experiência e identidade no assunto. As questões já estudadas e exauridas em outros países devem servir como exemplo, porém não devem ser o principal propulsor das ações no território nacional. Para que o Brasil assuma a sua identidade com objetivo de institucionalização e sistematização da prática de reúso de água em todo o território nacional, mesmo considerando as suas dimensões continentais e as distintas características gerais entre as suas regiões, estudos de avaliação de potencial devem ser conduzidos anteriormente à realização dos empreendimentos. Trata-se de uma ferramenta de planejamento, necessária para alcance do êxito. Muitos projetos de sistemas de abastecimento de água e de esgotamento sanitário, no país, não alcançam os objetivos, muitas vezes, em função da falta de planejamento. É nesse cenário que a presente Nota Técnica apresenta elementos essenciais para o desenvolvimento de uma metodologia de planejamento para a condução de estudos de avaliação de potencial de reúso regional de água no Brasil. Nessa metodologia são abordados aspectos relacionados à delimitação da área de estudo, às localizações e aos levantamentos de possíveis fontes de oferta e demanda de água de reúso, bem como as ferramentas de avaliação de potencial e de análise espacial, que possibilitam a elaboração de mapas que favorecerão as tomadas de decisão. Para as possíveis ofertas e demandas de água de reúso, são ainda indicados passos para análise quantitativa e qualitativa de forma a permitir o melhor conhecimento das suas particularidades e definir fatores de otimização eventualmente necessários para o alcance de qualidade desejada para os diferentes tipos de reúso pretendidos.

Palavras-chave: ofertas de água de reúso; demandas de água de reúso; otimização de ETEs; distância e transporte; análise espacial.

\section{Abstract}

Water reuse is a topic of widespread and development in various regions of the world. In Brazil, its application is recent and still incipient. Thus, the country must still build its own experience and identity in the matter. Issues already studied and exhausted in other countries should serve as an example, but they should not be the main propulsion of actions in the national territory. For Brazil to assume its identity with the objective of institutionalizing and systematizing the practice of water reuse throughout the national territory, even considering its continental dimensions and the distinct general characteristics between its regions, 
potential assessment studies must be caried out prior to the achievement of the enterprises. It is a planning tool, necessary to achieve success. Many projects for water supply and sewage systems in the country do not achieve the objectives, often due to the lack of planning. It is in this scenario that this Technical Note presents essential elements for the development of a planning methodology for carrying out studies to evaluate the potential of regional water reuse in Brazil. In this methodology, aspects related to the study area delimitation, locations, and surveys of possible sources of water reuse offer and demand are addressed, as well as the potential assessment tools and spatial analysis, which enable the elaboration of maps that will favor decision making. For the possible offers and demands of reused water, steps are also indicated for quantitative and qualitative analysis to allow the best knowledge of their particularities and to define optimization factors that may be necessary to achieve the desired quality for the different types of reuse intended.

Keywords: water reuse offers; water reuse demand; optimization of WWTP; distance and transport; spatial analysis.

\section{INTRODUÇÃO}

Cerca de 2 bilhões de pessoas no planeta vivem em países de elevado estresse hídrico; aproximadamente dois terços da população mundial vivem em situação de escassez hídrica severa, no mínimo um mês ao ano (WWAP, 2019). Os fatores que contribuem para o agravamento desse cenário estão associados ao crescimento populacional, às mudanças climáticas, à poluição generalizada dos corpos hídricos e ao desenvolvimento econômico desconectado da sustentabilidade. A discussão sobre a falta de água para os usos pretendidos, em diversas regiões, $e$ as alternativas de minimização desses impactos levam em consideração aspectos relacionados à quantidade e à qualidade da água disponível, aos índices de coleta e tratamento de esgotos, ao lançamento inadequado de esgoto bruto nos corpos hídricos, aos conflitos pelo uso dos recursos ambientais (SOUZA et al., 2017; ANGELAKIS et al., 2018), às perdas de água nos sistemas de distribuição (SANTOS e VIEIRA, 2020) e aos desperdícios, de maneira geral.

No Brasil, no ano de 2018, o índice médio de perdas de água nos sistemas de distribuição alcançou quase $40 \%$. Na região Nordeste, onde se enfrentam os maiores desafios de escassez hídrica no país, as perdas alcançaram $46,0 \%$. Manaus, capital do estado do Amazonas, e Porto Velho, capital do estado de Rondônia, apresentam índices de perda superiores a $75 \%$ (BRASIL, 2019). Em relação a coleta e tratamento de esgotos, o Brasil apresenta índices muito distantes do conceito da universalização. Menos de $60 \%$ da população urbana brasileira é atendida por coleta de esgoto e menos de $40 \%$ do esgoto gerado no país é tratado; estados como Acre, Amazonas, Amapá, Maranhão, Rondônia e Pará, apresentam esses índices abaixo dos 15\% (ANA, 2020a). Destes, Amapá, Rondônia e Pará apresentam índices ainda piores, inferiores a $10 \%$. No estado do Maranhão, a sua capital, São Luís, apresenta somente $4 \%$ de esgoto tratado e apesar do município de Caxias, o segundo maior do estado, apresentar $100 \%$ de atendimento com serviço de esgotamento sanitário, $95 \%$ da população é atendida com sistemas individual, nomeadamente fossa séptica (ANA, 2017a).

Além dos baixos índices de coleta e tratamento de esgotos, é importante destacar a qualidade dos efluentes tratados. Segundo Lima et al. (2020a), até $2017,30 \%$ da vazão total tratada no Brasil passava somente por etapa primária ou primária avançada, garantindo desempenho médio de redução de matéria orgânica da ordem de 60\%; e apenas 7\% da vazão total tratada no Brasil passava por etapa terciária de desinfecção. Não há dúvida da urgência tanto de aumento desses índices de atendimento, como também de otimização das unidades existentes e em operação, para geração de efluentes de melhor qualidade de forma a minimizar a poluição de corpos hídricos, proteger a saúde pública e produzir água de reúso para as regiões mais afetadas pela seca. Ainda, de forma a garantir a conservação e o uso racional da água, é premente a necessidade de redução dos índices de perda nos sistemas de distribuição de água.

Em função das diferentes características socioeconômicas, culturais e ambientais presentes entre as regiões brasileiras, a gestão de recursos hídricos e de saneamento no país apresenta grandes desafios. Por certo, a escassez dos recursos hídricos e o aumento das 
demandas de água para o abastecimento humano, para o setor industrial e para atividades agrícolas, impulsionam o desencadeamento dos conflitos pelos usos da água. Torna-se assim inevitável a necessidade da conservação e do uso racional da água, do tratamento adequado dos esgotos e do reúso de água, como ferramentas de gestão de recursos hídricos e saneamento (ASANO et al., 2007). A água reciclada, recuperada ou de reúso é reconhecida pela Organização das Nações Unidas como uma fonte alternativa e confiável para o suprimento de grande parte das demandas hídricas existentes no mundo (WWAP, 2017).

A institucionalização da prática de reúso prevê a sua adoção de forma sistêmica e a sua inserção na matriz hídrica regional. Dessa forma, de acordo com Hespanhol (2008), a prática deve ser aplicada com o objetivo de cobrir demandas parciais ou totais dos diversos usos consuntivos (aqueles que consideram consumo efetivo de água), não somente em regiões de baixa disponibilidade hídrica (áridas e semiáridas), mas também naquelas em que as demandas de água são excessivamente elevadas ou acima da capacidade de oferta. Essas regiões acabam sendo palcos de conflitos pelos usos múltiplos da água e sofrem restrições de consumo, afetando diretamente o seu desenvolvimento econômico.

O planejamento adequado deve ser o principal fator para o suprimento das demandas regionais, quando se trata do reúso de água. Nesse caso, um importante instrumento de gestão e planejamento estratégico são o estudo do potencial regional e o levantamento das ofertas e das demandas para este fim.

Araujo et al. (2019) avaliaram o potencial do reúso para áreas irrigadas na bacia hidrográfica do Piancó-Piranhas-Açu e concluíram que $8 \%$ da demanda para a agricultura poderia ser suprida com a água de reúso, com o potencial atualmente disponível. Destaca-se ainda que essa região, inserida no Semiárido brasileiro, possui baixo índice de tratamento de esgotos, evidenciando a absoluta necessidade de aumento desses índices também para fins de reúso. Lima et al. (2020a) realizaram estudo similar, com a elaboração de uma metodologia de levantamento de potenciais de reúso de água para todas as regiões hidrográficas brasileiras, onde foram levantadas as demandas para irrigação e as ofertas de água de reúso para cada uma delas. Melo et al. (2020) avaliaram o potencial de reúso em uma bacia hidrográfica do rio Paracatu, em Minas Gerais, que atualmente vive situações de conflito pelo uso da água. Nesse estudo, os autores propuseram uma metodologia com uso de Sistema de Informação Geográfica (SIG) para alocação espacial tanto das instalações de oferta de água de reúso, como das áreas de demanda de água.

O SIG é uma ferramenta importante para apoiar tecnicamente estudos de avaliação das potencialidades da aplicação da água de reúso. A partir das bases de dados georreferenciadas, entre as diversas possibilidades, é possível fazer análise espacial sobrepondo as informações em diferentes camadas, de acordo como os objetivos pretendidos. Essa análise, que pode ser visualizada em mapas elaborados para cada área de estudo, permite relacionar as informações mais relevantes para cada caso, tais como: as distâncias entre produtores e consumidores; características que envolvam as culturas a serem irrigadas versus a qualidade de água produzida em cada ETE; os tipos de equipamentos de irrigação alocados em cada área; entre outras informações. O acesso a essa base de dados pode ser disponibilizada aos usuários de forma ilustrativa ou interativa. $O$ formato interativo permite acesso técnico para atualização de dados, facilita a visualização e a compreensão, além de proporcionar aos gestores uma ferramenta de tomadas de decisão mais assertivas.

O conjunto das Notas Técnicas (NT), perfazendo quatro conteúdos, tem como principal objetivo a proposição de uma metodologia estruturada de avaliação do potencial regional de reúso de água no Brasil. Seu foco principal é a inserção dessa fonte alternativa na matriz hídrica regional dentro do território nacional, de forma a propiciar o avanço do planejamento dos recursos hídricos e saneamento, como também, auxiliar gestores e tomadores de decisão. A presente Nota Técnica (NT03) propõe uma metodologia de potencialidades regionais de reúso de água, com a delimitação da área de estudo, o levantamento das demandas e ofertas, e a análise espacial para visualização em mapas.

\section{DELIMITAÇÃO DA ÁREA DE ESTUDO}

A concepção de um projeto de reúso de água deve ser uma etapa criteriosa e com planejamento adequado, de forma a garantir o sucesso do empreendimento, a segurança e o atendimento dos objetivos pretendidos. A 
delimitação da área de estudo é parte fundamental desse processo, podendo se apresentar em diferentes escalas (Figura 1).

Em geral, as concepções de reúso de água na escala meso são realizadas no âmbito dos limites administrativos estaduais e municipais. Isso se dá, em função de os órgãos reguladores e os órgãos gestores de recursos hídricos e de meio ambiente serem definidos nesses contextos institucionais. Os potenciais geradores de água de reúso na escala meso são as empresas operadoras de sistemas de esgotamento sanitários, tais como concessionárias estaduais (públicas ou privadas), sistemas autônomos de água e esgoto e autarquias públicas municipais. Um exemplo da delimitação de uma área de estudo estadual refere-se ao projeto contratado pela Empresa Baiana de Saneamento (EMBASA), denominado Estudo de Avaliação de Potencialidades de Reúso de Efluente Sanitário Tratado no Estado da Bahia, que avaliou o potencial de reúso de água nos 367 municípios baianos abrangidos pela companhia. No contexto municipal, pode-se observar com mais detalhamento 0 exemplo do município de Campinas, operado pela SANASA (Sociedade de Abastecimento de Água e Saneamento de Campinas/SP), apresentado na NT01.

Fora desse contexto dos limites administrativos públicos, e inseridos na escala macro do gerenciamento dos recursos hídricos, destacam-se as regiões hidrográficas ou ainda em menor escala, as bacias hidrográficas. A Política Nacional de Recursos Hídricos (PNRH) (BRASIL, 1997) estabeleceu que a gestão das águas (federais e estaduais) no território nacional deve ser realizada no âmbito da bacia hidrográfica. Mais tarde, a Resolução do Conselho Nacional de Recursos Hídricos (CNRH) no 32 definiu a divisão hidrográfica em função de regiões hidrográficas mais abrangentes (BRASIL, 2003). Essas divisões visaram o atendimento das necessidades de gestão de recursos hídricos com as configurações físicas e características locais (PORTO e PORTO, 2008).

\section{Figura 1: Fluxograma das diferentes escalas que podem ser abordadas na delimitação} da área de estudo

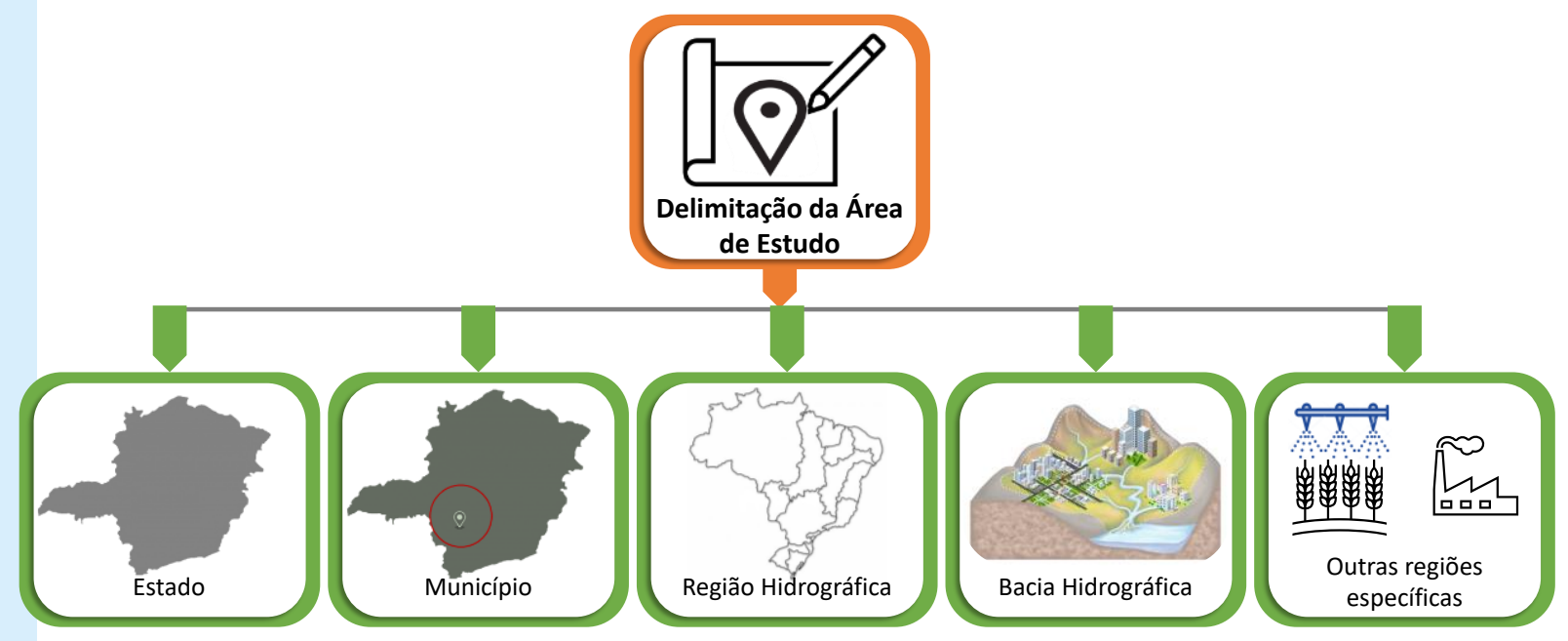

Fonte: Elaborado pelos autores.

A gestão dos recursos hídricos é descentralizada, onde as decisões são deliberadas na instância dos Comitês de Bacia Hidrográfica (CBH) (BRASIL, 1997). De acordo com ANA (2020b), esses comitês são compostos por representantes do poder público, dos usuários e da sociedade civil interessados nos usos múltiplos da água. De maneira resumida, os comitês têm as seguintes competências: i) promover o debate entre as partes interessadas; ii) arbitrar conflitos entre usuários; iii) aprovar o plano da bacia, e acompanhar sua execução; iv) propor usos insignificantes para efeitos de isenção de outorga; v) estabelecer a ferramenta da cobrança; e vi) estabelecer critérios para rateio de custos das obras de usos múltiplos. Portanto, no contexto da inserção da água de reúso na matriz hídrica, cabe ao $\mathrm{CBH}$ incluir fontes alternativas no planejamento estratégico de recursos hídricos da bacia, para atendimento de demandas atuais ou futuras, minimização de conflitos, redução do lançamento de carga 
orgânica dos efluentes, além do estabelecimento de mecanismos para cobrança pelo uso dessa água.

Frequentemente, na gestão das bacias hidrográficas e das regiões hidrográficas, 0 planejamento da inclusão da água de reúso na matriz hídrica pode ser facilitado em função da especificidade atribuída a esses fóruns. Melo et al. (2020), Lima et al. (2020a) e Santos et al. (2018) apresentam diferentes metodologias de planejamento, que podem ser adotadas como exemplos para outros estudos aplicados a outras áreas, inclusive com a definição de novas variáveis alinhadas com outros objetivos.

De maneira mais localizada, regiões de estudo como polos industriais, áreas irrigadas (públicas e privadas), ou sistemas descentralizados podem ser delimitadas de acordo com os objetivos dos gestores. Nesses casos, as especificidades já são intrínsecas à escala, o que pode facilitar consideravelmente 0 planejamento e a concepção do empreendimento (exemplos podem ser observados na abordagem da NT01 e uma discussão mais aprofundada sobre a gestão integrada de sistemas centralizados e descentralizados para planejamento de reúso de água nos ambientes urbanos, na NT04). No caso do reúso de água em edificações urbanas, que caracterizam sistemas descentralizados, Gonçalves, Keller e Franci (2019) apresentaram um estudo comparativo entre Brasil e Alemanha, com dados de consumo de água, distribuição do consumo nas residências, potencial de reúso nas edificações, tecnologias mais utilizadas e custo de implantação, operação e manutenção.

Independentemente do âmbito (estado, município, região hidrográfica, bacia hidrográfica ou outras regiões específicas), a delimitação da área de estudo deve envolver aspectos e passos sequenciais com a abordagem de diferentes variáveis, conforme apresentadas no Quadro 1.

Por fim, é importante observar que a área de estudo deve ser delimitada de acordo com a área de abrangência do projeto, com os objetivos alinhados no âmbito da gestão de recursos hídricos e saneamento e em um contexto de planejamento estratégico adequado (Ver NT02).

\section{LEVANTAMENTO E LOCALIZAÇÃO DAS OFERTAS}

Ao se delimitar a área de estudo, é necessário observar a localização das ofertas
(EPAR) a nível regional. Nesse sentido, a principal base de dados para consulta de informações sobre ETEs é o Atlas Esgotos, um relatório que levantou dados de sistemas de esgotamento sanitário nos municípios brasileiros entre os anos de 2013 e 2015 (ANA, 2017a) e foi atualizado recentemente, em 2020 (ANA, 2020a). Nesse relatório são abordados os dados relativos à cobertura de atendimento aos serviços de esgotamento sanitário existentes (coleta, coleta e tratamento, solução individual) e com dados de: localização, tecnologia de tratamento, vazão, eficiência média de remoção de matéria orgânica, entre outros. Esse documento vem sendo amplamente utilizado na gestão de saneamento devido ao grau de refinamento das informações, quando comparado às alternativas existentes (LIMA et al., 2020b).

Mesmo diante de dados secundários, é importante verificar a disponibilidade dos dados reais para garantia de maior rigor da informação, além de atualização das informações préexistentes. Os principais dados referentes às ETEs de interesse para esse tipo de projeto são: localização georreferenciada, vazão média (atual e futura), tecnologias de tratamento, desempenho e qualidade final do efluente. É importante que sejam identificados também eventuais planos de expansão da capacidade de tratamento das EPARs de interesse. Essa etapa de aprofundamento consiste no levantamento de dados primários diretamente com o responsável pelos serviços de saneamento local, em especial, no setor operacional das estações. Esses dados devem, preferencialmente, ser compostos por séries históricas de vazão de operação da estação, e características físico-químicas e microbiológicas do efluente após o tratamento. A partir desse relatório, recomenda-se uma análise dos dados para verificação das flutuações das concentrações, assim como variações das vazões para assegurar que essas oscilações e variações não prejudiquem uma operação de reúso adequada. Para este caso, pode ser suficiente o desenvolvimento de uma análise simples de estatística descritiva, a partir dos seguintes parâmetros:

- Número de dados: quantidade de dados utilizados na análise;

- Medidas de tendência central: representam a tendência de agrupamento de dados em torno de um valor central, tais como média e 
mediana;

- Medidas de dispersão e variação de dados: usadas para avaliar o grau de variabilidade de um conjunto de dados numéricos, tais como desvio padrão e coeficiente de variação;

- Medidas de localização relativa: permite comparar dados e agrupá-los em categorias, (quartis de 10\%, 25\%, 75\%, $90 \%$ ), ou determinar a posição exata de valores (mínimo e máximo);

- Distribuição de frequência: são faixas de valores nas quais pode ser dividida a amostra e suas respectivas frequências de ocorrência.

\section{Quadro 1: Variáveis relacionadas à delimitação da área de estudo}

\begin{tabular}{|c|c|}
\hline Variável & Explicação \\
\hline $\begin{array}{l}\text { Localização das } \\
\text { ofertas (LO) }\end{array}$ & $\begin{array}{l}\text { A localização das unidades, atuais e futuras, que podem fornecer água de } \\
\text { reúso (ETE ou EPAR) é de grande relevância, sendo considerada uma das } \\
\text { principais variáveis. É importante definir as ofertas, de modo a estabelecer } \\
\text { critérios de fornecimento, tais como quantidade, qualidade, transporte e } \\
\text { outros. Ter uma unidade de tratamento de esgotos em operação não } \\
\text { significa, de imediato, ter disponibilidade para o reúso. }\end{array}$ \\
\hline $\begin{array}{l}\text { Localização das } \\
\text { demandas (LD) }\end{array}$ & $\begin{array}{l}\text { A localização das demandas, de maneira análoga à localização das } \\
\text { unidades de oferta de água de reúso, é igualmente considerada prioridade. } \\
\text { Essa variável deve prever as diferentes áreas, com distintos objetivos de } \\
\text { demandas (atuais e futuras) que se encontram nas proximidades das } \\
\text { unidades de oferta. Neste caso, podem ser elencadas áreas de conflitos } \\
\text { pelo uso da água, áreas mais impactadas pela seca, áreas de expansão de } \\
\text { atividades agrícolas ou industriais, entre outras. }\end{array}$ \\
\hline $\begin{array}{l}\text { Análise de qualidade } \\
\text { (AQ) }\end{array}$ & $\begin{array}{l}\text { A qualidade atualmente apresentada pelo efluente deve ser uma variável } \\
\text { de destaque, já que pode inclusive demandar otimização da ETE para } \\
\text { atender os objetivos de reúso ou mesmo melhorar aspectos operacionais. } \\
\text { Uma avaliação criteriosa da série histórica de qualidade dos efluentes das } \\
\text { potenciais Estações Produtoras de Água de Reúso (EPAR) é } \\
\text { recomendada. }\end{array}$ \\
\hline $\begin{array}{l}\text { Avaliação de } \\
\text { distâncias (AD) }\end{array}$ & $\begin{array}{l}\text { É sabido que as distâncias entre unidades de oferta e áreas de demanda } \\
\text { de água de reúso podem ser fatores limitantes para alavancar os } \\
\text { empreendimentos. Distâncias muito elevadas podem apresentar custos de } \\
\text { transporte inviáveis, seja ele realizado por caminhão ou por adução. No } \\
\text { caso do transporte por adução, deve-se avaliar ainda o desnível } \\
\text { geométrico entre os pontos de produção e de destino da água de reúso. }\end{array}$ \\
\hline $\begin{array}{l}\text { Listagem de áreas } \\
\text { prioritárias (LAP) }\end{array}$ & $\begin{array}{l}\text { Em regiões de escassez hídrica, os gestores podem se deparar com mais } \\
\text { de uma área carente de água, inclusive com demandas de diferentes } \\
\text { modalidades de reúso. Assim, é importante hierarquizar as áreas } \\
\text { prioritárias, de acordo com os objetivos definidos, que podem ser: aumento } \\
\text { da produção agrícola, impulsionamento do desenvolvimento } \\
\text { socioeconômico, redução de conflitos, melhoria da qualidade de corpos } \\
\text { hídricos, entre outros. Destaca-se que essa hierarquização deve ser } \\
\text { baseada, com mais peso, em critérios técnico/científicos do que em } \\
\text { critérios políticos. }\end{array}$ \\
\hline $\begin{array}{l}\text { Estudo preliminar de } \\
\text { custo (EPC) }\end{array}$ & $\begin{array}{l}\text { O estudo de custo deve ser realizado de maneira preliminar e em ordem de } \\
\text { grandeza, de forma a subsidiar e orientar as tomadas de decisão e os } \\
\text { passos futuros para o estabelecimento dos empreendimentos prioritários. }\end{array}$ \\
\hline
\end{tabular}


Conforme apresentado por ANA (2020a), $34 \%$ das ETEs em operação no Brasil alcançam, atualmente, somente 0 nível secundário de tratamento, com eficiência de redução de matéria orgânica acima de $80 \%$. Para fins de reúso, a grande maioria apresenta desempenho desprezível em relação à redução de organismos indicadores de contaminação fecal; somente $9 \%$ apresentam lagoas de maturação em seus fluxogramas, caracterizando desinfecção.

Nesse contexto, é importante ainda avaliar a necessidade de melhoria das unidades atualmente em operação e instaladas na área de estudo, para atendimento dos objetivos de reúso. Essa otimização pode levar em consideração: i) somente adequações operacionais para alcance do desempenho esperado para as tecnologias implantadas; ii) melhorias tecnológicas dos processos atualmente instalados; e iii) complementação ou alteração do fluxograma atualmente instalado, com novos processos tecnológicos mais adequados aos objetivos pretendidos. No caso das ETEs ainda em planejamento todo o projeto deve ser concebido para a produção de água de reúso com a qualidade almejada, de forma a minimizar trabalhos futuros. Esse tipo de planejamento, com uma visão sistêmica por parte dos gestores, é fundamental para o desenvolvimento do setor nas regiões de estudo.

A depender do porte do projeto, caso este envolva um conjunto de estações a serem analisadas, é possível criar uma métrica para categorização das unidades de tratamento. Lima et al. (2020a) adotaram os termos "Categoria 01" (efluente secundário com remoção de matéria orgânica superior a $80 \%$ ), "Categoria 02 "( efluente desinfetado) e "Sem Categoria" (efluentes que apresentam desempenho inferior às demais categorias). É importante notar que as adequações necessárias à prática de reúso são mais exequíveis em plantas com, no mínimo, a etapa secundária em operação. Contudo, a existência de uma tecnologia secundária não resulta, necessariamente, em um efluente de qualidade compatível com o aproveitamento, uma vez que diversos fatores influenciam no seu desempenho, como: qualidade de operação e manutenção da estação, e adequação do projeto à realidade do sistema de esgotamento sanitário. A partir da classificação anterior e dos dados do efluente da ETE, recomenda-se dividir a próxima etapa de análise das ofertas em termos qualitativos e quantitativos. A qualidade do efluente é fundamental para a definição da(s) unidade(s) adicional(is) de tratamento e a finalidade da água de reúso. Em demandas mais restritivas pode ser necessária a implementação de um sistema terciário para o polimento do efluente secundário, contemplando uma etapa de desinfecção ou até mesmo de remoção de nutrientes. Dessa forma, tanto a destinação da água de reúso quanto seus respectivos padrões requeridos serão responsáveis por determinar o nível de tratamento necessário na EPAR.

O Programa Interáguas (INTERÁGUAS, 2017) destacado na NT01 indica tecnologias de tratamento de esgoto sanitário alinhadas aos padrões de qualidade de água para cada modalidade de reúso. Em linhas gerais, são indicados os sistemas compostos por etapa secundária seguida por desinfecção direta, ou etapa secundária seguida por desinfecção em duplo estágio (INTERÁGUAS, 2017). Segundo Araujo (2019), a desinfecção em duplo estágio (filtração terciária seguida de desinfecção) apresenta uma água de melhor qualidade, ao garantir melhor desempenho na desinfecção, em função de uma unidade de filtração (areia, carvão e outros) à montante da desinfecção, para fins de redução de turbidez.

A localização da ETE, bem como as tecnologias adotada no processo de tratamento, são os fatores que mais influenciarão na viabilidade financeira do reúso (ARAUJO; SANTOS; SOUZA, 2017; MELO et al., 2020). Em relação à localização, essa viabilidade se dá, principalmente, devido aos custos envolvidos em cada modalidade de transporte da água da estação ao consumidor. Em geral, o uso de caminhões-pipa é o mais comum, tendo em vista sua adaptabilidade em atender diferentes consumidores menores, com demandas esporádicas e baixo custo inicial, quando comparado à alternativa de adutoras. Contudo, o transporte por tubulações se mostra mais viável com grandes volumes a consumidores fixos, assim como menores custos de operação. Já em relação às tecnologias adotadas no processo, diferentes qualidades de água podem ser alcançadas a partir de diferentes arranjos tecnológicos, implicando diretamente na viabilidade dos empreendimentos em termos de custos de implantação, operação e manutenção, além da complexidade operacional. Conforme destacado na NT01, há que se levar ainda em consideração a manutenibilidade dos empreendimentos de reúso, que geram 
incertezas quanto à aplicabilidade e à continuidade do projeto para implantação de adutoras, bem como o uso de combustível fóssil para uma aplicação sustentável de água de reúso.
Na Figura 2, encontra-se apresentado um diagrama esquemático dos principais aspectos discutidos anteriormente sobre o levantamento e a localização das ofertas de água de reúso.

\section{Figura 2: Diagrama esquemático dos principais aspectos relacionados ao levantamento e localização das ofertas de água de reúso}

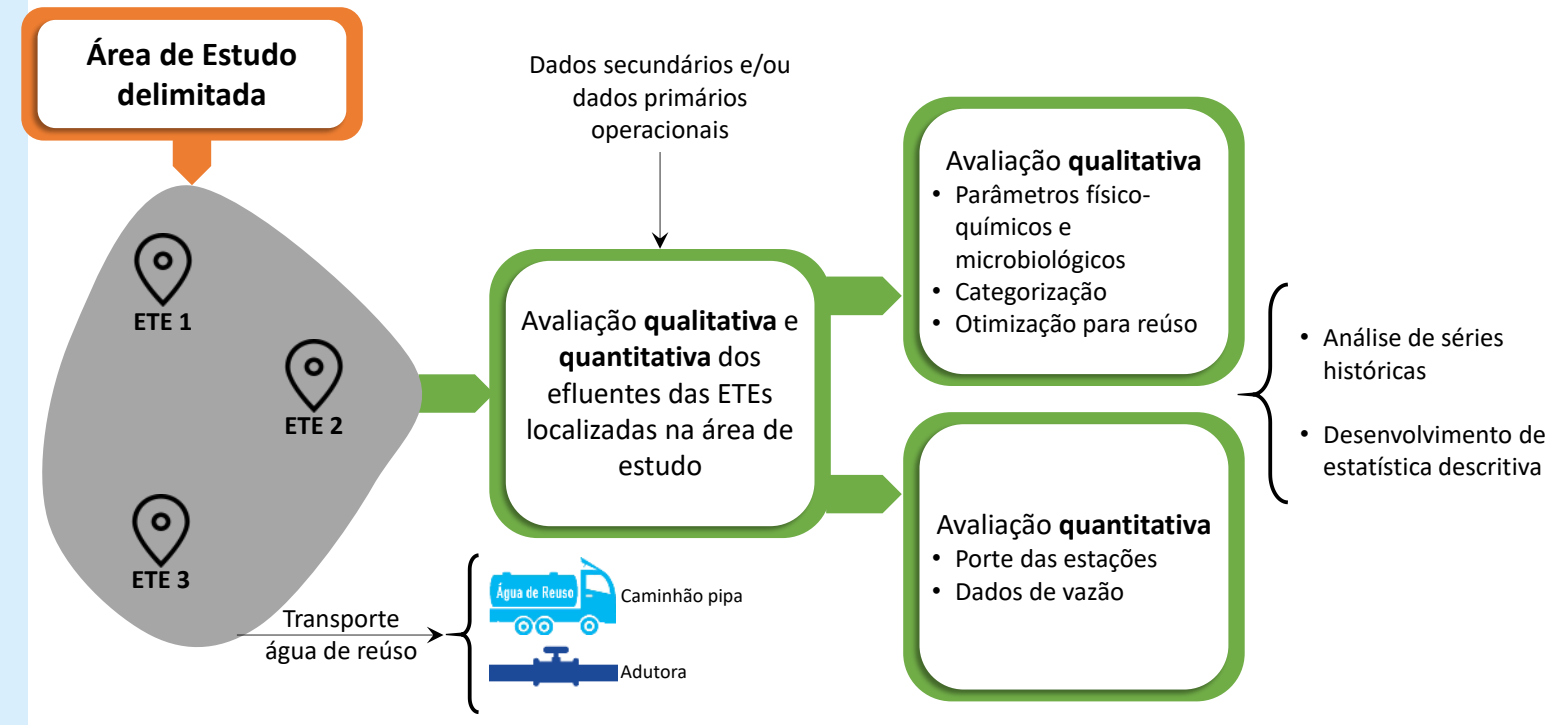

Fonte: Elaborado pelos autores.

\section{LEVANTAMENTO E LOCALIZAÇÃO DAS DEMANDAS}

As demandas de água estão relacionadas aos seus usos múltiplos, destacados pela Resolução do Conselho Nacional do Meio Ambiente (CONAMA), no 357/2005, tais como abastecimento doméstico e industrial, irrigação, dessedentação de animais, e outros (BRASIL, 2005). Os usos em que a água é consumida no seu processo produtivo, diminuindo a disponibilidade de água do corpo hídrico para usos futuros, são considerados usos consuntivos, e.g. usos industriais, abastecimento público, irrigação etc. Já os usos que não exercem consumo de água e não afetam diretamente a sua quantidade, são considerados não consuntivos, e.g. geração de energia hidroelétrica, navegação, recreação etc. (ANA, 2019). De forma ainda mais aplicada, a ANA, apresenta uma relação entre a água retirada e a água efetivamente consumida no Brasil, para usos como abastecimento urbano, rural, animal e industrial, irrigação, mineração e termelétricas. No ano de 2019, a média anual total de água retirada foi de aproximadamente $2 \mathrm{mil} \mathrm{m}^{3} / \mathrm{s}$, enquanto a média anual total de água consumida foi em torno de $1 \mathrm{mil} \mathrm{m} 3 / \mathrm{s}$, representando no geral, uma relação de $50 \%$ de consumo efetivo em relação à retirada. Tanto em termos de retirada como de consumo, a irrigação aparece com os maiores percentuais em relação aos demais usos: quase $50 \%$ da água retirada e $66 \%$ da água consumida (ANA, 2020b). Ressalta-se que a relação entre retirada e consumo de água na irrigação, referese principalmente à água que a cultura usa para desenvolvimento, além da eficiência dos sistemas de irrigação; os mais eficientes colaboram para valores mais próximos entre água consumida e água retirada.

É nesse contexto de gestão de recursos hídricos que a água de reúso se insere como uma fonte alternativa para demandas específicas. Nota-se assim, a relevância do levantamento da demanda de água na região de estudo, tanto para o conhecimento dos usos múltiplos e suas vazões perenes e sazonais, como para gerenciamento dos recursos hídricos, de maneira geral. O trabalho desenvolvido por Melo et al. (2020) teve como pano de fundo exatamente o cenário de avaliação do potencial de reúso de água em uma região de conflito pelo uso da água, em função 
dos seus usos múltiplos.

Para a obtenção de dados necessários para - levantamento, bem como a localização e a caracterização das demandas de água na área de estudo, existem diversas fontes, com destaque para os documentos públicos da Agência Nacional de Águas e Saneamento Básico e os bancos de dados (federal e estaduais) de outorga de direito pelo uso da água. Outras fontes de informações podem também ser utilizadas, tais como levantamentos de associações do setor industrial e agrícola, além de documentos técnico-científicos desenvolvidos no âmbito da academia e informações sobre grandes consumidores de água detidas por prestadoras de serviços de saneamento.

\section{Documentos públicos da Agência Nacional de Águas e Saneamento Básico}

O Sistema Nacional de Informações sobre Recursos Hídricos (SNIRH) é uma ferramenta prevista na PNRH. Trata-se de um amplo banco de dados de coleta, tratamento, armazenamento e divulgação de informações sobre recursos hídricos, onde se enquadram uma série de documentos e manuais que a ANA vem produzindo, referentes aos usos de água em diferentes contextos regionais do país. Assim, os dados consolidados no SNIRH servem como ferramentas de apoio à gestão e planejamento dos recursos hídricos. Entre os documentos publicados pela ANA sobre a temática, destacamse as publicações que possuem abrangência nacional para a obtenção dos dados de demanda e descritas com maiores detalhes no Quadro 2.

\section{Quadro 2: Documentos da ANA para a obtenção dos dados de demanda de água}

\begin{tabular}{|c|c|}
\hline Documento & Descrição \\
\hline $\begin{array}{l}\text { Conjuntura dos recursos } \\
\text { hídricos (publicados } \\
\text { anualmente entre } 2009 \text { e } \\
\text { 2020) }\end{array}$ & $\begin{array}{l}\text { O primeiro relatório "Conjuntura dos recursos hídricos" foi publicado em } 2009 \text { e } \\
\text { é atualizado anualmente com novas informações. O documento mais recente é } \\
\text { o "Informe 2020", onde são apresentadas: as demandas de água, por } \\
\text { finalidade, para o ano de 2019; o total de retiradas e consumos de água por } \\
\text { Região Hidrográfica; o perfil do uso da água nas Unidades de Gestão de } \\
\text { Recursos Hídricos (UGRHs); as maiores retiradas por finalidade; e outros. } \\
\text { Trata-se de uma referência para o acompanhamento sistemático da situação } \\
\text { dos recursos hídricos no país, através de um conjunto de indicadores e } \\
\text { estatísticas sobre a água e sua gestão. Neste caso, todas as informações } \\
\text { apresentadas são de domínio público e alimentam o SNIRH. }\end{array}$ \\
\hline $\begin{array}{l}\text { Manual de usos consuntivos } \\
\text { de água (2019) }\end{array}$ & $\begin{array}{l}\text { Nesse estudo, foram disponibilizados os resultados de estimativas dos usos } \\
\text { consuntivos para todos os municípios brasileiros desde } 1931 \text { até o ano de } \\
\text { publicação do estudo, além da projeção para 2030. A categorização das } \\
\text { demandas foi realizada por modalidade (irrigação, abastecimento urbano, rural } \\
\text { e industrial, uso animal, mineração e termelétrica), com definição da vazão } \\
\text { correspondente para cada uma delas e por localidade. }\end{array}$ \\
\hline $\begin{array}{l}\text { Atlas irrigação: uso da água } \\
\text { na agricultura irrigada } \\
(2021)\end{array}$ & $\begin{array}{l}\text { O Atlas Irrigação, publicado originalmente em } 2017 \text { e atualizado em } 2021 \text {, tem } \\
\text { como um dos objetivos o suprimento da carência de dados relativos à } \\
\text { agricultura irrigada, agregando a esses, dados de recursos hídricos na escala } \\
\text { nacional. No documento, é abordado o histórico da agricultura irrigada, o } \\
\text { contexto atual e o cenário para } 2040 \text {. As demandas de irrigação são } \\
\text { apresentadas referentes às médias anuais por tipologia (arroz, café, cana-de- } \\
\text { açúcar irrigada e fertirrigada, culturas anuais em pivôs centrais e outras } \\
\text { culturas e sistemas) e unidade da federação. }\end{array}$ \\
\hline $\begin{array}{l}\text { Água na indústria: uso e } \\
\text { coeficientes técnicos (2017) }\end{array}$ & $\begin{array}{l}\text { O estudo estimou as demandas hídricas por tipologia de indústria de } \\
\text { transformação a partir de coeficientes técnicos baseados no número de } \\
\text { trabalhadores. As demandas para o setor industrial são apresentadas de } \\
\text { diferentes maneiras: relação de municípios com vazões de retirada superiores } \\
\text { a } 1 \mathrm{~m}^{3} / \mathrm{s} \text {; proporção da demanda hídrica industrial por região brasileira; vazões } \\
\text { de consumo e de retorno em relação à vazão retirada por tipologia industrial; } \\
\text { proporção das vazões consumidas por tipologia industrial, entre outros. }\end{array}$ \\
\hline
\end{tabular}

Fonte: ANA (2017b); ANA (2019a); ANA (2020b); ANA (2021).

Links disponíveis para consulta dos documentos produzidos pela ANA abordados no Quadro 2: Conjuntura dos Recursos Hídricos; Manual de usos consuntivos de água (2019); Água na indústria: uso e coeficientes técnicos (2017); Atlas Irrigação (2021). 


\section{Bancos de dados (federal e estaduais) de outorga de direito pelo uso da água}

A outorga de direito de uso da água é um instrumento de gestão previsto na PNRH e tem o objetivo de disciplinar os usuários, garantir um controle quantitativo e qualitativo, para preservar os usos múltiplos deste recurso, bem como assegurar 0 direito de acesso aos usuários (BRASIL, 1997). A lei estabelece a necessidade de uma autorização pelo direito de uso da água nas atividades que geram impactos quantitativos e qualitativos, relacionados diretamente aos seus usos. As unidades federativas e a união, por meio dos órgãos estaduais de gestão de recursos hídricos e a ANA, respectivamente, detém uma base consolidada de dados relacionada aos usos outorgados da água em nível estadual e federal, o Cadastro Nacional de Usuários de Recursos Hídricos (CNARH). Essa base de dados é de acesso público e nela constam cerca de $80 \%$ de todos os usuários regularizados no país (ANA, 2020b). O CNARH se configura como uma das mais importantes ferramentas disponíveis para o levantamento de demandas de água em estudos de avaliação de potencial regional de reúso de água.

É importante destacar que os usuários podem ser cobrados pelo uso da água e nem todos os usos possuem a necessidade de outorga. Na prática, os setores sujeitos a essas cobranças, no Brasil, são prestadores de serviços de saneamento, indústria, geradores de energia hidrelétrica e agricultura (OCDE, 2017).

$\mathrm{Na}$ presente Nota Técnica, a outorga de direito pelo uso da água é abordada como um importante dado para levantamento de usos da água no território nacional. Entretanto, quando alinhada à cobrança pelo seu uso, revela um relevante aspecto econômico para 0 desenvolvimento de projetos e infraestruturas no contexto da bacia hidrográfica. Neste sentido, destaca-se essa relevância (cobrança pelo uso da água) e posteriormente, retoma-se o conteúdo específico relacionado à ferramenta "outorga" como dado para levantamento de usos da água.

O domínio das águas no Brasil é dividido entre os estados e a união. As águas de domínio da união compreendem os rios e lagos que banham mais de um estado, os que se encontram nos limites com outros países e os terrenos marginais, além das praias fluviais (BRASIL, 1988). Já as que compreendem o domínio estadual são as águas superficiais e subterrâneas que nascem e desaguam dentro do território de um único estado (ANA, 2020b).

\section{Cobrança pelo uso da água}

A cobrança pelo uso da água é um instrumento econômico, que não tem caráter de imposto ou tarifa. Trata-se de uma remuneração pelo uso desse bem público de acesso comum, com valor e mecanismos de cobrança definidos no âmbito dos Comitês de Bacia Hidrográfica e agências, de forma participativa de usuários de água, sociedade civil e autoridades públicas (ANA, 2014; ARAUJO et al., 2018; OCDE, 2017). Essa cobrança tem três objetivos principais que se interrelacionam: i) indicar o valor econômico da água; ii) incentivar o seu consumo responsável, consciente e racional; e iii) preservar a sua qualidade (BRASIL, 1997; OCDE, 2017). Ainda como consequência, a cobrança pelo uso da água arrecada recursos financeiros para aplicação em projetos e intervenções no âmbito dos planos de recursos hídricos (BRASIL, 1997). O valor arrecadado deve ser aplicado, de preferência, na própria bacia, com o intuito de incentivar o investimento na despoluição dos mananciais, no reúso de água, na proteção e na conservação dos recursos hídricos e no emprego de tecnologias mais sustentáveis e econômicas (ANA, 2014). Destaca-se ainda a cobrança pelo lançamento de efluente, que, quando do seu aproveitamento, deixa de ser realizada.

Segundo OCDE (2017), em 2016, foram gerados cerca de 548 milhões de reais a partir da cobrança pelo uso de recursos hídricos sob domínio da União e cerca de 1,5 bilhão de reais sob domínio estadual. A nível da União, essas receitas podem cobrir aproximadamente de 10 a $15 \%$ da necessidade de financiamento para implementar ações previstas nos Planos de Recursos Hídricos, tais como estudos, projetos ou obras. A bacia do rio Paraíba do Sul foi o primeiro caso de aplicação de cobrança pelo uso de recursos hídricos no Brasil, além do estado do Rio de Janeiro. Atualmente, já se encontram com mecanismos de cobrança implementados, as bacias dos rios Piracicaba, Capivari, Jundiaí (PCJ), do rio São Francisco e dos rios Doce, Paranaíba e Verde, além dos estados do Ceará, Minas Gerais, São Paulo, Paraná e Paraíba.

Em relação às vazões outorgadas vigentes nos mananciais, no ano de 2017, as de domínio da união foram responsáveis pela captação de $1.270 \mathrm{~m}^{3} / \mathrm{s}$ de água e as estaduais, de 1.989 
$\mathrm{m}^{3} / \mathrm{s}$; no ano de $2019,1.557 \mathrm{~m}^{3} / \mathrm{s}$ de água foram captados em rios de domínio da união e 2.781 $\mathrm{m}^{3} / \mathrm{s}$ em rios estaduais (ANA, 2019b; ANA, 2020b). As três modalidades que demandam 0 maior quantitativo de vazão outorgada são 0 abastecimento urbano/rural, a indústria e a irrigação. Juntas, correspondem a $93 \%$ do total outorgado, onde a irrigação é responsável por $68 \%$ (ANA, 2020b).

Os dados referentes ao levantamento de outorga das captações dos rios federais e estaduais podem ser facilmente obtidos no portal da ANA. Com o objetivo de facilitar o acesso ao leitor, disponibiliza-se aqui o "Link de Outorgas". As informações referentes às outorgas são distribuídas em diferentes categorias, como, "Unidade Federativa", "Finalidade", "Comitê Federal", "Comitê Estadual", entre outros. Por fim, pode-se realizar a compilação dos dados desejados da área de estudo e obter os valores de demanda por finalidade. Muitos órgãos estaduais de gestão de recursos hídricos também disponibilizam dados de outorga de água em seus domínios, para o acesso público. No estudo de potencial de reúso de água desenvolvido por Melo et al. (2020), o levantamento de demandas foi realizado a partir dos dados de outorga superficiais emitidas e disponibilizadas no Sistema Integrado de Dados Ambientais (SIAM), do Instituto Mineiro de Gestão das Águas (IGAM), por se tratar de um rio de domínio do estado de Minas Gerais.

\section{AVALIAÇÃO DAS POTENCIALIDADES}

Diante de todos os dados que podem ser obtidos por meio da metodologia descrita até o momento, a avaliação das potencialidades se torna um caminho mais fácil, onde devem ser levados em consideração aspectos técnicos, econômicos, culturais, sociais, ambientais e políticos nas tomadas de decisão. Inicialmente, é importante definir a metodologia a ser adotada na avaliação em questão, com a definição e priorização de etapas, conforme apresentado no Quadro 3.

Além das etapas relacionadas diretamente aos projetos de reúso, destacadas no Quadro 3, outras mais gerais merecem atenção, tais como a avaliação de outorgas de lançamento de efluente e a avaliação da existência de outras fontes, que não as superficiais. No primeiro caso, destaca-se, a possível necessidade de manutenção de vazão de lançamento para usos a jusante em regiões que apresentam criticidade quantitativa. A segunda leva em consideração a articulação do reúso com a dessalinização em regiões costeiras, como abordado na NT04 e a abundância de poços em algumas regiões, conforme evidenciado por meio de outorgas.

$\mathrm{Na}$ Figura 3, pode-se observar um fluxograma para visualização das interações entre as etapas destacadas como fundamentais para a metodologia de avaliação de potenciais de reúso regional de água (Quadro 3). Novamente, chamase a atenção para os diferentes portes e especificidades de cada projeto. Em casos específicos, outras variáveis podem ser acrescentadas e algumas aqui apresentadas podem ser suprimidas, caso seja conveniente.

Os aspectos de quantidade e qualidade, tanto da oferta como da demanda requerida, bem como os aspectos de distância entre eles, levam necessariamente, à avaliação de tipos de transporte e reservação da água de reúso, bem como à otimização necessária para atendimento à qualidade desejada para os tipos de reúso pretendidos. Essa otimização pode ser realizada com a inclusão de um processo de desinfecção (em único ou duplo estágio) nas instalações da própria ETE, ou pode-se prever o encaminhamento do efluente para uma EPAR em área (espacial e/ou administrativa) fora dos limites da ETE. Na Figura 4, são apresentados 3 arranjos possíveis que levam em consideração essas variáveis: a) Efluente da ETE encaminhado para a EPAR, b) otimização da ETE para produção de água de reúso (reservação externa); c) otimização da ETE para produção de água de reúso (reservação interna).

Diante das etapas destacadas no Quadro 3 e alinhadas no fluxograma da Figura 3, diferentes metodologias de avaliação de potencial regional de reúso de água podem ser adotadas:

1) Metodologia geral de prioridades: normalmente em projetos de grande porte, onde vários cenários são possíveis, as prioridades (técnicas, socioeconômicas, ambientais ou políticas) são definidas para avanço de definição dos arranjos de implantação. Nesse caso, as prioridades podem ser tanto relacionadas às ofertas como às demandas, embora em geral sejam relacionadas à demanda.

2) Metodologia baseada na otimização das ETEs: também presentes em projetos de 
grande porte, quando muitos cenários são apresentados, adotam-se aqueles que demandam menos intervenções de otimização nas ETEs para alcance das qualidades e das quantidades de água desejadas. ETEs com fluxogramas a nível secundário, em geral, demandam somente uma desinfecção para alcance de qualidade para diferentes tipos de reúso.

3) Metodologia baseada em cenário de escassez extrema: ocorre em situações já alarmantes de escassez extrema de água, onde o reúso é a única opção e deve ser aplicado imediatamente. Vale ressaltar, que mesmo em necessidade imediata, as etapas de planejamento não devem ser negligenciadas.

4) Metodologia de demandas específicas: ocorre quando há uma demanda específica de um potencial consumidor de água de reúso. Este caso é muito comum em sistemas descentralizados, onde já há uma demanda da própria edificação ou indústria.

5) Metodologia de planejamento: ocorre em situações específicas de planejamento no contexto da gestão de recursos hídricos, mesmo em situações de disponibilidade hídrica satisfatória. Seria o caso ideal para ser aplicado anteriormente à demanda excessiva em função de cenários recorrentes de estresse hídrico.

\section{Quadro 3: Etapas a serem percorridas na avaliação de potencial}

\begin{tabular}{|c|c|}
\hline Etapa & Observação \\
\hline Quantitativo de oferta & $\begin{array}{l}\text { Pode-se avaliar em relação à vazão instalada e à vazão futura. Por ser ainda uma } \\
\text { fase de planejamento, é possível se discutir o potencial para a vazão existente e } \\
\text { para a vazão esperada em novos projetos de sistemas de esgotamento sanitário. } \\
\text { O regime de vazões deve ser detalhado, objetivando a compatibilização da } \\
\text { produção com o consumo no tempo. }\end{array}$ \\
\hline Quantitativo de demanda & $\begin{array}{l}\text { Demandas de água de reúso podem ser maiores ou menores e a possibilidade de } \\
\text { supri-las é um ponto alto nessa fase de avaliação. Essa discussão pode ser feita } \\
\text { com base em demandas atuais e futuras. As variações temporais da demanda } \\
\text { devem ser especificadas, pelo mesmo motivo citado anteriormente } \\
\text { (compatibilização da produção com o consumo no tempo). }\end{array}$ \\
\hline $\begin{array}{l}\text { Qualidade do efluente } \\
\text { ofertado }\end{array}$ & $\begin{array}{l}\text { Em termos qualitativos, as categorias de efluente descritas anteriormente, } \\
\text { favorecem a avaliação de potencial. Diferentes qualidades de efluentes são } \\
\text { indicadas para distintas qualidades requeridas por cada tipo de reúso. }\end{array}$ \\
\hline $\begin{array}{l}\text { Qualidade requerida na } \\
\text { demanda }\end{array}$ & $\begin{array}{l}\text { Qualidades mais baixas requeridas pelos potenciais usuários são mais facilmente } \\
\text { alcançadas. Por outro lado, qualidades altas requerem grandes esforços na } \\
\text { otimização das ETEs e maiores custos. }\end{array}$ \\
\hline $\begin{array}{l}\text { Otimização requerida na } \\
\text { ETE }\end{array}$ & $\begin{array}{l}\text { Uma avaliação entre qualidade ofertada e qualidade requerida, inevitavelmente } \\
\text { será a responsável pela avaliação da otimização requerida tanto em ETEs } \\
\text { existentes como em ETEs em fase de projeto. O balanço hídrico entre produção e } \\
\text { consumo também pode exigir adaptações na infraestrutura. }\end{array}$ \\
\hline $\begin{array}{l}\text { Distâncias entre ofertas } \\
\text { e demandas }\end{array}$ & $\begin{array}{l}\text { O estabelecimento das distâncias em linha reta e em rodovias, entre as ofertas e } \\
\text { demandas é uma etapa de grande relevância para a avaliação. }\end{array}$ \\
\hline Tipos de transporte & $\begin{array}{l}\text { As distâncias em rodovia, entre ofertas e demandas, facilitam a avaliação do } \\
\text { transporte por caminhão. Já as distâncias em linha reta, bem como características } \\
\text { de relevo, vegetação, solo e ocupação do solo, quando possível, facilitam a } \\
\text { avaliação do transporte por tubulação. }\end{array}$ \\
\hline $\begin{array}{l}\text { Instalação de } \\
\text { reservatórios }\end{array}$ & $\begin{array}{l}\text { Em geral, a instalação de reservatórios se faz necessária para atender as } \\
\text { sazonalidades das demandas. Essa etapa também pode ser realizada com uma } \\
\text { interação entre as distâncias e as características das diferentes qualidades de } \\
\text { efluentes, podendo-se avaliar uma possível mistura para aumento de vazão. } \\
\text { Ressalta-se aqui a necessidade de medidas para evitar o recrescimento de } \\
\text { microrganismos, como a pós-cloração. }\end{array}$ \\
\hline $\begin{array}{l}\text { Tipos de reúso } \\
\text { pretendidos }\end{array}$ & $\begin{array}{l}\text { Os diferentes usos pretendidos serão consequência do uso e ocupação do solo da } \\
\text { área de estudo. Se vários usos possíveis estiverem disponíveis, é possível fazer } \\
\text { uma relação com a qualidade requerida e consequentemente, a otimização } \\
\text { necessária para a ETE. }\end{array}$ \\
\hline
\end{tabular}


Figura 3: Fluxograma de interação das etapas essenciais na avaliação de potencialidades de reúso regional de água

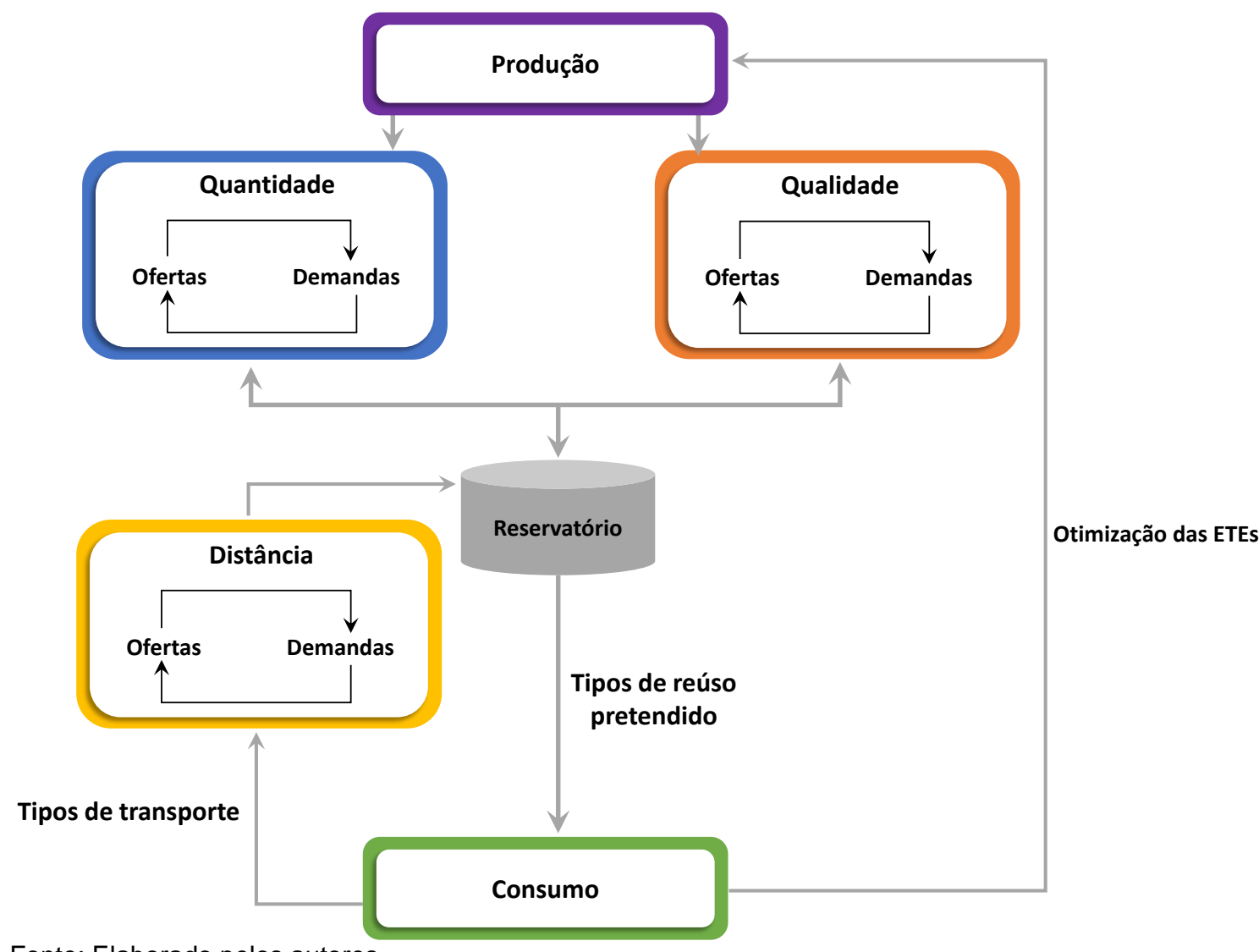

Fonte: Elaborado pelos autores.

Figura 4: Arranjos de otimização da ETE, além de aspectos de reservação e transporte para atendimento aos tipos de reúso pretendidos.

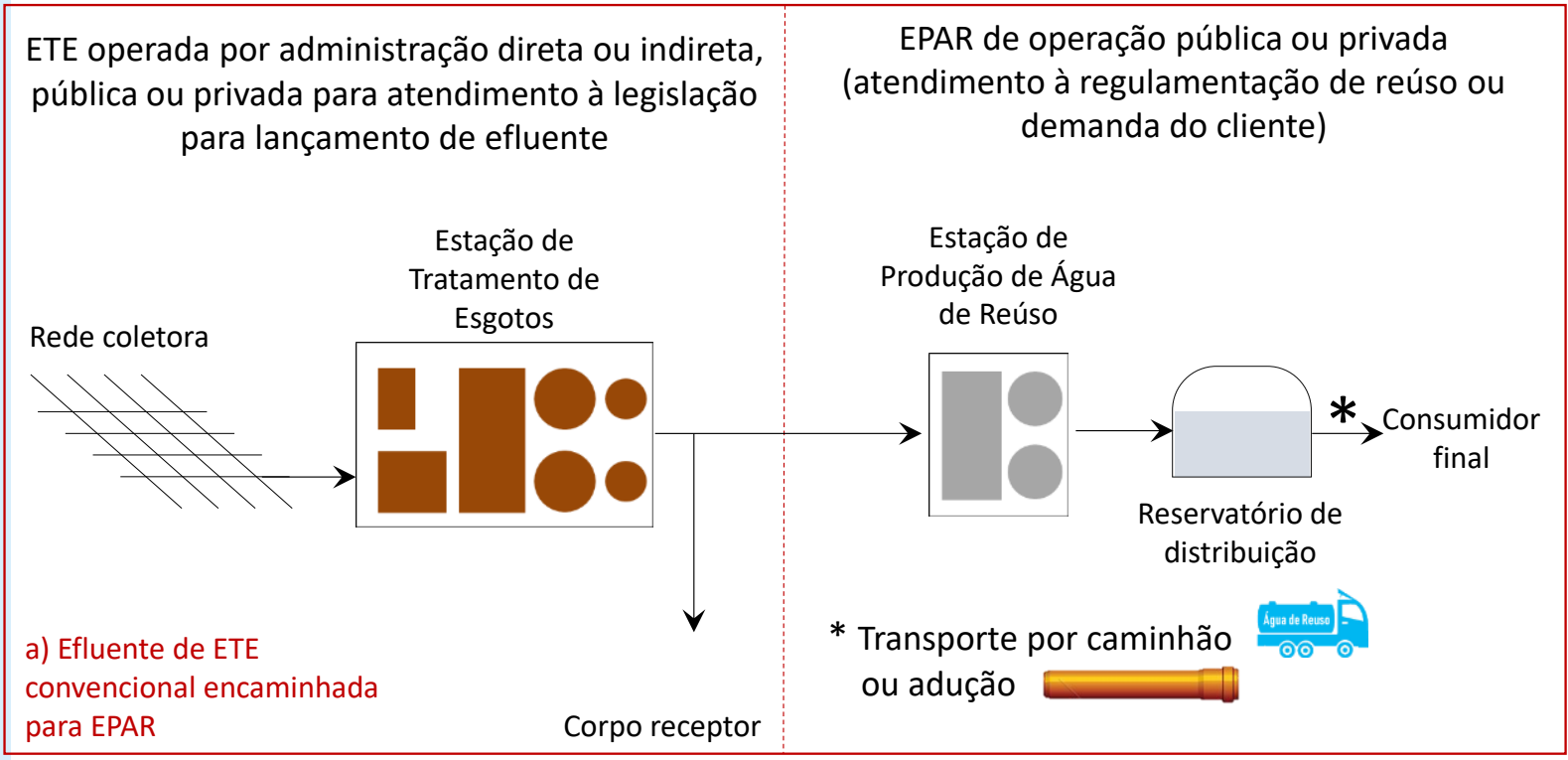

Continua na próxima página. 


\section{Continuação da Figura 4.}

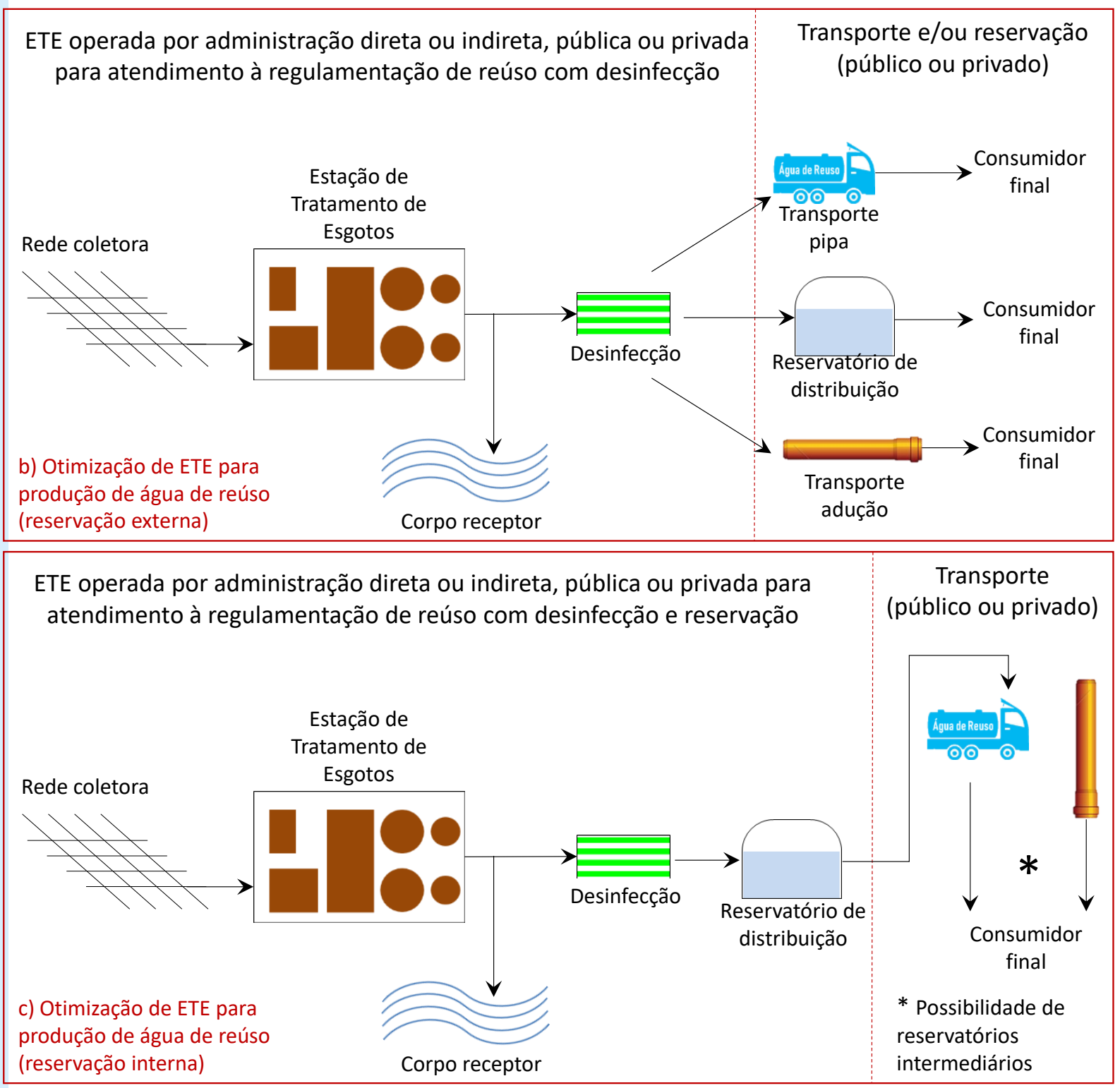

Fonte: Elaborado pelos autores.

As metodologias destacadas podem ser adotadas em separado, conjuntamente ou até mesmo com novos aspectos não especificados. Outro caminho para essa análise seria ainda a criação de diferentes cenários tais como: Atual atendimento atual em relação ao abastecimento de água e o esgotamento sanitário; Futuro ampliação dos índices de coleta e tratamento de esgoto conforme planejamento local e; Ideal projeção do aumento desses índices em relação à cobertura com abastecimento de água.

Ainda, programas e matrizes qualitativas de análise de potencial podem ser indicadas para facilitar as tomadas de decisão. Entretanto, a visualização das variáveis e etapas em mapas temáticos, de preferência com sobreposição de camadas, produzidos no contexto do projeto, deve ser também considerada.

\section{ANÁLISE ESPACIAL PARA TOMADA DE DECISÃO}

Devido à complexidade e ao alto volume de dados da fase de construção do diagnóstico e avaliação do potencial de reúso de água, nomeadamente em projetos de grande porte, é importante sistematizar os dados a fim de validar todo o conteúdo produzido. Nesse sentido, a visualização para as tomadas de decisão mais assertivas é favorecida em mapas produzidos a partir de um Sistema de Informação Geográfica (SIG), que se apresenta como uma ferramenta 
essencial para compilar e consolidar os dados coletados e analisados durante o diagnóstico.

Através do SIG, é possível desenvolver um banco de dados, modelar as informações e, por fim, produzir mapas ilustrativos que possibilitam o uso destas informações de forma interativa e prática pelos interessados. Em síntese, o SIG permite a identificação, caracterização, georreferenciamento, quantificação e qualificação das potencialidades de oferta e demanda para 0 reúso de água na área estudada. Essa possibilidade de organizar as informações coletadas no diagnóstico e analisá-las espacialmente é uma potente ferramenta de apoio à gestão. Entre as diversas decisões que podem ser auxiliadas, destacam-se: a avaliação de ampliação e otimização de sistemas de tratamento existentes; a concepção de novos sistemas de tratamento com vistas ao reúso de água; a localização de reservatórios estratégicos de água de reúso; a logística de transporte (por caminhão ou por adução); a estimativa de custos de transporte; a localização de novos empreendimentos de reúso de água; e a estimativa de custos de implantação de novas unidades.

Ressalta-se que é desejável a produção de painéis interativos, com interface simplificada, e disponíveis ao usuário do sistema de informações, de forma a trazer a possibilidade de inserção de novos dados, correção ou atualização. Entretanto, em função das características específicas e do porte de cada projeto, é possível desenvolvê-lo com menos recursos e disponibilizá-los sob a forma de mapas ilustrativos, que oferecem apenas um recorte temporal da situação.

De maneira geral, a análise espacial deve buscar interrelacionar tanto as variáveis destacadas no Quadro 1 (referentes à delimitação da área de estudo), como as etapas destacadas no Quadro 3 (referentes à avaliação de potencial). Em resumo, sugerem-se os seguintes dados:

- LO e LD de água de reúso com dados qualitativos e quantitativos, de acordo com a $A Q$ realizada na fase de delimitação da área de estudo;

- Diferenciação (por cores ou formatos) de níveis de potenciais ofertas e demandas;

- Em relação às ETEs em estudo, localização dos atuais pontos de lançamento dos efluentes;
- $A D$ em linha reta entre potenciais usuários e oferta de água de reúso;

- Marcação de rodovias para facilitar estimativas de distância entre ofertas e demandas, bem como de custos relacionados ao transporte, permitindo o EPC;

- Marcação de pontos notáveis como referência de localização e/ou que podem se apresentar como empecilhos na logística de transporte, como áreas de preservação;

- Marcação de regiões de interesse como delimitação de estados, municípios e bacias hidrográficas;

- Hidrografia e disponibilidade hídrica das bacias hidrográficas;

- LAP com diferenciação de cores ou formatos, associando tabelas de visualização numérica;

- Informações relevantes em camadas de relevo, uso e ocupação do solo, vegetação, condições climáticas, tipos de culturas e equipamentos de irrigação predominantes em contexto de reúso na agricultura, e outros específicos para cada projeto.

Os mapas resultantes dessa análise espacial devem apresentar informações claras e objetivas, de acordo com o porte e as especificidades de cada projeto. Importante salientar que os dados que serão passíveis de sistematização e análise espacial estão diretamente relacionados à qualidade de dados disponíveis no momento do diagnóstico. Na Figura 5 estão apresentados três mapas elaborados no âmbito do estudo realizado por Melo et al. (2020), com diferentes objetivos, usando diferentes camadas de informação para sua representação.

$\mathrm{Na}$ Figura 6, encontra-se apresentado um exemplo de mapa interativo do Portal da Infraestrutura Nacional de Dados Espaciais (INDE), somente a título de exemplo. Para visualização desse mapa, foi escolhido o estado do Rio de Janeiro, e as camadas de "disponibilidade hídrica" (com sua respectiva legenda) e de "localização das Estações de Tratamento de Esgotos".

Os mapas ilustrativos da Figura 5, embora não disponham de interação com as diferentes camadas de informação, também são importantes e desejáveis para apresentação em relatórios e projetos. Contudo, ressalta-se que esses são 
produzidos de acordo com cada objetivo e conjunto de dados. Caso haja alguma alteração de objetivo (seja desejável visualizar outra camada), ou atualização dos dados, o processo de análise espacial e de elaboração do mapa deve ser refeito. Portanto, esses mapas ilustrativos são ferramentas para a avaliação de potencial e tomadas de decisão que retratam 0 momento específico (objetivos e dados) no qual foi gerado. Em contrapartida, os bancos de dados e painéis interativos, exemplificados na Figura 6, fornecem ao usuário a flexibilidade de sobreposição de camadas e atualização, em tempo real, de novos inputs no banco de dados. Dessa forma, permitem tomadas de decisão mais precisas e dinâmicas em relação às alterações das variáveis. Apesar das suas diferenças, ambos possuem aplicações e relevâncias específicas e são utilizados em função dos diferentes contextos de cada projeto.

No caso dos bancos de dados e painéis interativos, ressalta-se que, após conclusão e entrega, é fundamental que haja a transferência do conhecimento através da capacitação da equipe de geoprocessamento responsável. Assim, o usuário responsável por operar e alimentar o sistema com os dados terá condições de proceder novas análises e melhorias que possam surgir a partir de outras demandas.

Figura 5: Mapas estáticos elaborados para estudo de avaliação de potencial de reúso em bacia hidrográfica

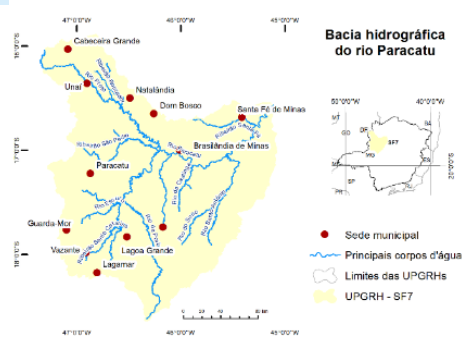

a) Localização da BH de estudo, sedes municipais e principais corpos d'água.

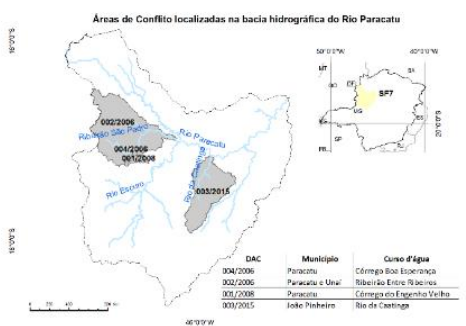

b) Áreas de conflito pelo uso da água na bacia de estudo.

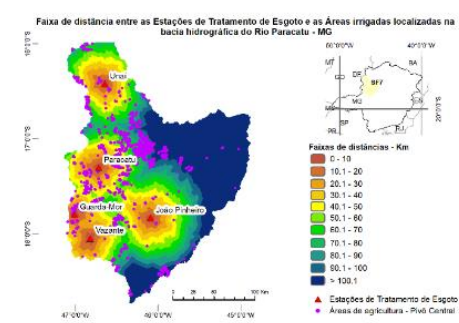

c) Representação das distâncias entre as ETEs e os pivôs de irrigação na BH.

Fonte: Traduzido de Melo et al. (2020).

Figura 6: Mapa interativo - Estado do Rio de Janeiro, disponibilidade hídrica e estações de tratamento de efluentes

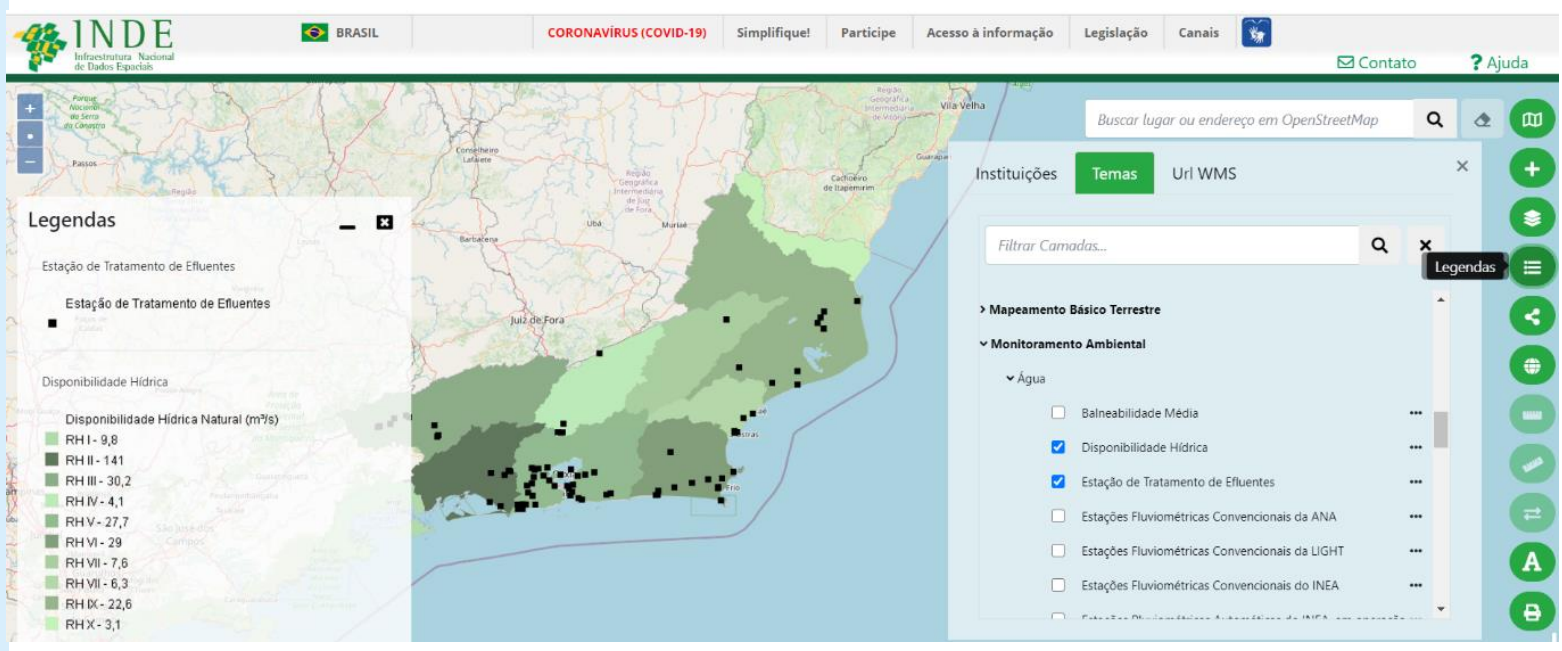

Fonte: Elaborado pelos autores no ambiente eletrônico do Portal INDE (2021). 


\section{CONSIDERAÇÕES FINAIS}

Na presente Nota Técnica, foi apresentada uma metodologia específica para a avaliação de potencialidades de reúso de água em uma determinada região de estudo. Nesse sentido, especificou-se 0 detalhamento sobre a delimitação de área de estudo e as variáveis que a compõem (LO, LD, AQ, AD, LAP e EPC), definidas no Quadro 1. Posteriormente, foram atribuídas especificidades relacionadas às potenciais ofertas e demandas de água, em função de suas localizações e levantamentos. De maneira geral, as potenciais ofertas são, basicamente, os efluentes das ETEs operadas nos limites da área de estudo; as potenciais demandas podem ser buscadas em diferentes fontes, com destaque para os documentos nacionais publicados pela ANA na base da dados do SNIRH e os dados de outorga de direito pelo uso da água, também disponibilizados pela ANA e/ou pelos órgãos estaduais de gestão de recursos hídricos. Tanto para os dados de possíveis ofertas como para os dados de possíveis demandas, sugere-se uma análise quali-quantitativa de dados históricos, baseada em uma estatística descritiva simples.
Posteriormente, deve-se desenvolver a avaliação de potencialidades, propriamente dita. Para essa avaliação são sugeridas etapas para análise e metodologias de execução. Por fim, todas as informações estudadas e sistematizadas podem ser agrupadas e georreferenciadas em ambiente SIG, que permita análise espacial dos dados sistematizados. Os resultados dessa fase, que podem ser materializados em painéis interativos ou mapas ilustrativos, são poderosas ferramentas para tomadas de decisão, com base em aspectos técnicos, econômicos, sociais, culturais, ambientais e políticos. Os bancos de dados e painéis interativos permitem a alimentação com novos dados, garantindo sua eficácia para planejamentos futuros; os mapas ilustrativos, indicados para projetos de portes mais reduzidos, são ferramentas estanques para as decisões mais imediatas, muito embora não devam ser tratados como menos importantes.

$\mathrm{Na}$ Figura 7, observa-se um fluxograma geral da metodologia de potencialidades regionais de reúso de água proposta, para facilitar o entendimento geral e auxiliar nos processos de tomada de decisão.

Figura 7: Fluxograma geral da metodologia de potencialidades regionais de reúso de água.

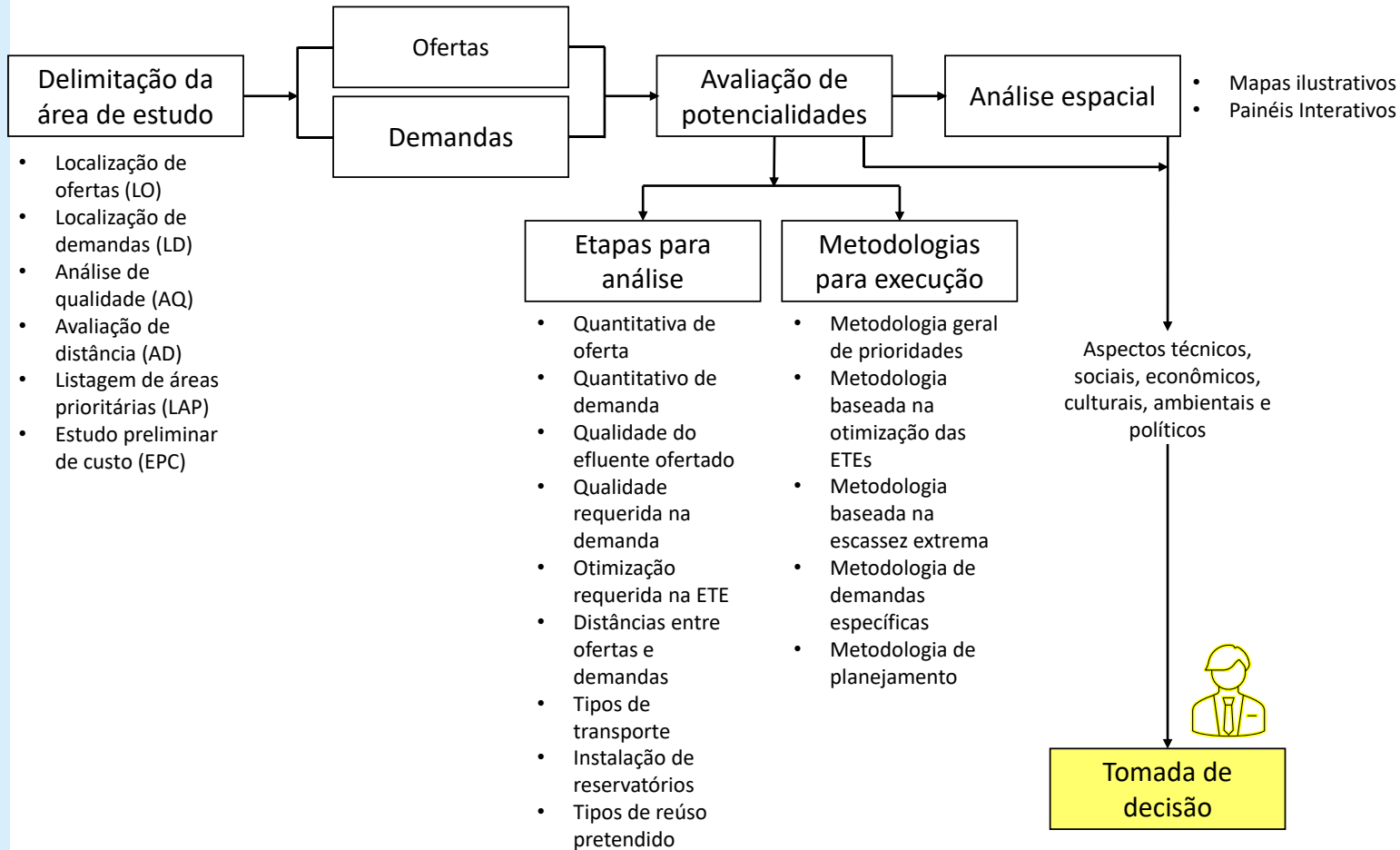

Fonte: Elaborado pelos autores. 


\section{AGRADECIMENTOS}

Os autores agradecem aos autores do artigo referenciado como Melo et al. (2020), de onde foram extraídos mapas, com o consentimento dos autores, para ilustração do conteúdo desta Nota Técnica.

\section{REFERÊNCIAS}

ANA. Agência Nacional de Águas (Brasil). Cobrança pelo uso de recursos hídricos. Capacitação de Recursos Hídricos v.7. Brasília, DF: ANA, 2014.

ANA. Agência Nacional de Águas (Brasil). Atlas esgotos: despoluição de bacias hidrográficas. Brasília, DF: ANA, 2017a.

ANA. Agência Nacional de Águas (Brasil). Água na indústria: uso e coeficientes técnicos. Brasília, DF: ANA, 2017b.

ANA. Agência Nacional de Águas (Brasil). Manual de Usos Consuntivos da Água no Brasil. Brasília, DF: ANA, 2019a.

ANA. Agência Nacional de Águas (Brasil). Outorga dos direitos de uso de recursos hídricos. Brasília, DF: ANA, 2019b.

ANA. Agência Nacional de Águas (Brasil). Atlas esgotos: atualização da base de dados de estações de tratamento de esgotos no Brasil. Brasília, DF: ANA, 2020a.

ANA. Agência Nacional de Águas e Saneamento Básico (Brasil). Conjuntura dos recursos hídricos no Brasil 2020: informe anual. Brasília, DF: ANA, 2020b.

ANA. Agência Nacional de Águas e Saneamento Básico (Brasil). Atlas Irrigação: uso da água na agricultura irrigada. Brasília, DF: ANA, 2021.

ANGELAKIS, A. N.; ASANO, T.; BAHRI, A.; JIMENEZ, B. E.; TCHOBANOGLOUS G. Water Reuse: From Ancient to Modern Times and the Future. Frontiers Environmental Science, v. 6, n. 26, 2018.

ARAUJO, B. M.; SANTOS, A. S. P.; SOUZA, F. P. Comparativo Econômico Entre o Custo Estimado do Reúso de Efluentes de ETE para Fins Industriais Não Potáveis e o Valor da Água Potável para a Região Sudeste do Brasil. Perspectivas Online, v. 17, p. 5161, 2017.

ARAUJO, B. M.; SANTOS, A. S. P.; SOARES, S. R. A.; MELO, M. C. DE; OHNUMA JUNIOR, A. A. Aspectos econômicos para o reúso na agricultura na Bacia do
Rio Paraíba do Sul e comparação com o modelo da gestão de cobrança em Israel. In: III Simpósio de Recursos Hídricos do Rio Paraíba do Sul, Juiz de Fora, MG, 2018. Anais [...], Juiz de Fora, MG, 2018.

ARAUJO, B. M. Avaliação da aplicabilidade da filtração terciária para condicionamento de efluente secundário a desinfecção por radiação ultravioleta. Dissertação (Mestrado) - Universidade do Estado do Rio de Janeiro, Faculdade de Engenharia. 2019.

ARAUJO, B. M.; SANTOS, A. S. P; LIMA, M. A. M.; SOARES, S. R. A.; PERDIGAO, C. A.; MELO, M. C. Avaliação do potencial de reúso de efluentes de ETE em áreas irrigadas da bacia hidrográfica PiancóPiranhas-Açu com vistas a universalização. Revista Augustus (UNISUAM. Online), v. 24, p. 179-191, 2019.

ASANO, T; BURTON, F.; LEVERENZ, H.; TSUCHIHASHI, R.; TCHOBANOGLOUS, G. Water reuse, issues, technologies, and applications. New York: Metcalf \& Eddy/AECOM, 1 ed., McGraw Hill, 2007.

BRASIL. Constituição da República Federativa do Brasil. Brasília, DF: Senado, p. 140, 1988.

BRASIL. Lei n. 9.433, de 8 de janeiro de 1997. Institui a Política Nacional de Recursos Hídricos, cria o Sistema Nacional de Gerenciamento de Recursos Hídricos. Diário Oficial da União. Brasília, DF. 1997.

BRASIL. Resolução CNRH no 32, de 15 de outubro 2003. Diário Oficial da União, Brasília, 17 de dezembro de 2003.

BRASIL. Resolução CONAMA no 357, de 17 de março de 2005. Dispõe sobre a classificação dos corpos de água e diretrizes ambientais para o seu enquadramento, bem como estabelece as condições e padrões de lançamento de efluentes, e dá outras providências. Diário Oficial da União, Brasília, 18 mar. 2005.

BRASIL. Ministério do Desenvolvimento Regional. Secretaria Nacional de Saneamento - SNS. Sistema Nacional de Informações sobre Saneamento: $24^{\circ}$ Diagnóstico dos serviços de água e esgoto - 2018, p. 180. Brasília, 2019.

GONÇALVES, R. F.; KELLER, R. P.; FRANCI, T. K. Análise comparativa das práticas de reúso de água cinza em edificações urbanas na Alemanha e no Brasil. Revista DAE, v. 67, p. 75-89, 2019.

HESPANHOL, I. Um novo paradigma para a gestão de recursos hídricos. Estudos Avançados, v. 22, n. 63, p.131-158, 2008. 
INDE. Infraestrutura Nacional de Dados Espaciais. 2021. Disponível em: https://visualizador.inde.gov.br. Acesso em: 8 de fev. 2021.

INTERÁGUAS - PROGRAMA DE DESENVOLVIMENTO DO SETOR ÁGUAS

Elaboração de proposta de plano de ações para instituir uma política de reúso de efluente sanitário tratado no Brasil. Produto III - Critérios de qualidade de água. Brasília. 2017.

LIMA, M. A. M; ARAUJO, B. M.; SOARES, S. R. A.; SANTOS, A. S. P.; VIEIRA, J. M. P.; Water reuse potential for irrigation in Brazilian hydrographic regions. Water Supply 2020, doi:

https://doi.org/10.2166/ws.2020.280. 2020a.

LIMA, M. A. M.; ARAUJO, B. M.; SOARES, S. R. A.; SANTOS, A. S. P. Uso do Atlas Esgotos: Despoluição de Bacias Hidrográficas no desenvolvimento de trabalhos científicos. Sustinere: Revista de Saúde e Educação, v. 8, p. 102-123, 2020b.

MELO, M. C.; SANTOS, A. S. P.; SANTOS, N. A. P.; ARAUJO, B. M.; OLIVEIRA, J. R. S.; CAMPOS, A. R. Evaluation of potential use of domestic treated effluents or irrigation in areas subject to conflicts over water use in Paracatu River Basin. Caminhos da Geografia (UFU. Online), v. 21, p. 52-63, 2020.

OCDE. Cobranças pelo uso de recursos hídricos no Brasil: Caminhos a seguir. Éditions OCDE, Paris, 2017.
PORTO, M. F. A.; PORTO, R. L. L. Gestão de bacias hidrográficas. Estudos Avançados, v. 22, n. 63, p. 4360, 2008.

SANTOS, A. S. P.; LIMA, M. A. M; RAMOS, L. T. A.; PEREIRA, C. B.; SOARES, S. R. A.; MELO, M. C. Capacidade de reúso de efluentes de Estações de Tratamento de Esgoto na Bacia Hidrográfica do Paraíba do Sul. Semioses (Rio de Janeiro), v. 12, p. 16-33, 2018.

SANTOS, A. S. P.; VIEIRA, J. M. P. Reúso De Água Para O Desenvolvimento Sustentável: Aspectos de regulamentação no Brasil e em Portugal. Revista Eletrônica de Gestão e Tecnologias Ambientais, v. 8, p. 50-68, 2020.

SOUZA, E. J. de; GAVAZZA, S.; FLORENCIO, L.; KATO, M. T. Níveis de adubação no cultivo de melancia irrigado com esgoto. Revista DAE, v. 65, p. 94-106, set. 2017.

WWAP. World Water Assessment Programme. The United Nations World Water Development Report 2017. Wastewater: The Untapped Resource. Paris, UNESCO. 2017.

WWAP. World Water Assessment Programme. The United Nations World Water Development Report 2019. Leaving No One Behind. Paris, UNESCO. 2019. 